\title{
Publishers' note
}

Dear subscriber to Indo-Iranian Journal [ISSN 0019-7246; online version1572-8536]

We would like to inform you that as of volume 52 (2009), this journal will be published by Brill (www.brill.nl), and no longer by Springer.

Subscribers should have received their 2009 renewal notice through Brill's offices, either direct or through their agent. If you have not received your renewal notice, please contact Brill directly. Your contact is Ms. Els van Egmond (Egmond@ brill.nl), Journal Marketing, Brill, P.O. Box 9000, 2300 RA Leiden, The Netherlands.

More information on the journal is now available at www.brill.nl/iij.

Sincerely,

Maja S.M. de Keijzer, Springer 